\title{
An EU Recycling Target: What Does the Dutch Evidence Tell Us?
}

\author{
Elbert Dijkgraaf $^{1} \cdot$ Raymond Gradus $^{2}$
}

Accepted: 4 May 2016 / Published online: 2 June 2016

(C) The Author(s) 2016. This article is published with open access at Springerlink.com

\begin{abstract}
The European Union (EU) advocates a household waste recycling rate of more than $65 \%$. Although the Netherlands has already invested heavily in recycling policies, this is still a big challenge as nowadays this rate is approximately $50 \%$ on average and very few no municipalities have a rate above $65 \%$. Given this practice, it is possible to learn from the Dutch experience which policies are effective in increasing recycling rates. Based on a large panel data set for the Netherlands, we show that unit-based pricing, avoiding a duo-bin for unsorted and compostable waste, and reducing the frequency of collecting unsorted and compostable waste at the curbside are effective in raising the recycling rate. However, only a bag-based pricing system has a substantial effect, but this policy can have some adverse effects. Other unit-based pricing systems have effects of less than $10 \%$ points. In nearly all cases, changing the frequency of collection of recyclables has no or very small effects. Moreover, the complementarity between unit-based pricing and curbside service is low. Overall, it seems very difficult to reach the EU goal of $65 \%$ with the policies applied.
\end{abstract}

Keywords Recycling · Waste policy · EU-target · Local government · Netherlands

JEL classification $\mathrm{Q} 18 \cdot \mathrm{Q} 38 \cdot \mathrm{R} 11 \cdot \mathrm{R} 15$

The authors like to thank two anonymous referees, Rob Aalbers and participants of a seminar at Netherlands Bureau for Economic Policy Analysis for comments on an earlier version.

$\triangle$ Elbert Dijkgraaf

dijkgraaf@ese.eur.nl

1 Erasmus School of Economics and Tinbergen Institute, Erasmus University Rotterdam, Rotterdam, The Netherlands

2 Faculty of Economics and Business Administration, VU University Amsterdam, Amsterdam, The Netherlands 


\section{Introduction}

Lack of space and a growing environmental awareness forced Dutch governments to take measures early on in the 1980s and 1990s to reduce the landfilling of unsorted (household) waste and to stimulate recycling. Later on, these measures were intensified with a tax on landfilling, a landfill ban and recently an incineration tax. Dutch municipalities are responsible for waste collection and they applied policies to stimulate the separation of waste. The way citizens pay for waste collection differs by municipality. Since the nineties, more and more Dutch municipalities have implemented unit-based user fees [see also Dijkgraaf and Gradus (2014)]. On average, Dutch municipalities recycled $50 \%$ of their waste in the period 19982012, which is still below the target of $65 \%$ as proposed by the European Commission in July 2014. The Dutch recycling rate, at approximately $50 \%$, is far above the EU average of $42 \%$ [see Eurostat (2014)]. In the past decade, it has been the Dutch administration's policy to increase recycling rates at the curbside. Despite heavy policy efforts such as separate curbside collection of paper, glass, plastics and compostable waste and the provision of special containers in many municipalities, the recycling rate dropped slightly from $50 \%$ in 1998 to $48 \%$ in 2012.

By law, Dutch municipalities are obliged to collect two types of waste at the curbside: unsorted (household) waste $^{1}$ and compostable waste such as vegetable, food and garden waste. Curbside collection of compostable waste started in January 1994. Its introduction was an important measure in increasing the amount of separately collected compostable waste. Furthermore, since 1994, the municipalities have been obliged to provide an infrastructure for the separate collection of glass, paper and textiles. They are not obliged, however, to collect these streams at the curbside. In most Dutch municipalities, recyclables can be discarded at drop-off facilities. Also in most Dutch municipalities, there is a curbside collection program for paper organized by local associations such as sports clubs and schools. In addition, since January 2010, municipalities are obliged by law to collect plastic packaging separately.

For the Netherlands, Dijkgraaf and Gradus (2014) show that between 1998 and 2010 there has been an increase in facilities at drop-off points in central locations for collecting different waste streams such as paper, glass, textiles and plastic packaging. Dutch door-todoor collection of recyclables increased as well-for compostable waste and paper at the end of the previous century and for plastics since 2009. In the literature, there is discussion about which method (curbside collection or drop-off centers) is most effective in collecting recyclables. For US municipal data, Beatty et al. (2007) show that the marginal impact of expanding curbside collection on recycled quantities is small, because curbside programs 'cannibalize' returns from drop-off centers. In fact, for aluminum and glass, the authors cannot reject the null hypothesis of no relationship between increased curbside access and the quantity recycled. However, for plastics, they find a significant relation between the percentage of the population served by curbside programs and the amount recycled.

Several Dutch municipalities introduced unit-based pricing (UBP) of unsorted and compostable waste as a measure to stimulate both the separate collection of recyclables and a reduction in the total amount of waste. In the last ten years, more and more Dutch municipalities have implemented unit-based user fees. By 2012, 36\% of Dutch municipalities had implemented such a system, while this share was only $15 \%$ in 1998. Based on 1998-2000 Dutch municipal data, Dijkgraaf and Gradus (2004) find sizeable and significant effects,

\footnotetext{
${ }^{1}$ In the Netherlands unsorted waste is all waste collected from households in a bag or bin except for separately collected recyclables like paper, glass, textile and compostables. Therefore, unsorted waste contains metals which are extracted before or after incineration.
} 
resulting in less unsorted and more recyclable waste. For the weight and bag-based system in the Netherlands, Dijkgraaf and Gradus (2004) reported a significant elasticity close to one for compostable waste and around 0.7 for unsorted waste. These elasticities are above those normally reported in the literature as shown in a meta-study by Bel and Gradus (2016). These elasticities are more in line with Huang et al. (2011) for US bag/tag-based system if the estimates are limited to UBP-municipalities. Based on data until 2005-2006 and corrected for environmental activism or municipal fixed effects, the effects of UBP-systems on the amount of waste still remain large [see Dijkgraaf and Gradus (2009) and Allers and Hoeben (2010)]. For the period 1998-2010, a similar picture is seen, although there is some evidence that especially the effectiveness of the administrative complex weight-based pricing system deteriorates over time [see Dijkgraaf and Gradus (2014)]. For the Netherlands, empirical evidence suggest that one fifth to a quarter of the UBP-reduction in unsorted waste is due to better recycling of paper, glass and textile, which are collected free of charge [see Allers and Hoeben (2010) and Dijkgraaf and Gradus (2014)]. Compostables are still a quarter of total waste, although the effect differs widely between the country-side and cities, and whether collection of compostables is penalized as well. Most of this literature is based on quantities and not on recycling rates. However, recently, Lakhan (2015) shows with Canadian municipal data that pay-as-you-throw (PAYT) schemes increase recycling rates significantly.

Other authors claim that non-monetary initiatives, such as the provision of frequent curbside recycling services, increase recycling as well [see, for example, Callan and Thomas (1997, 2001), Kinnaman and Fullerton (2000), Ferrera and Missios (2005), Kipperberg (2007) and Usui (2008)]. Based on UK municipal panel data, Abbott et al. (2011) study the determinants of dry recycling and composting rates separately. They suggest that in explaining the variation in the total recycling rate, it is helpful to disaggregate into dry and composting recycling. For composting, there is a complex relationship between the frequency of its collection, the collection frequency for residual waste and the type of container. In addition, Abbott et al. (2011) show that there is evidence that a lower collection frequency of residual waste increases dry recycling rates. This is interesting as some policy advisers in the Netherlands suggest that reducing the residual waste collection frequency could encourage recycling as well [see Reus and Jonkergouw (2013)].

For the Netherlands until now, no attention has been given to the effectiveness of curbside collection of recyclables. This was due to a lack of data. In this contribution, we fill this gap in the literature, using a large panel data set (1998-2012) for the Netherlands with information on local waste policies. In addition, we distinguish between unsorted, compostable, paper, glass, textile and plastic waste. ${ }^{2}$ Furthermore, we analyze whether the type of curbside container (mini-bin, duo-bin for two different types of waste, ${ }^{3}$ bag or crate) influences the results. We are also able to include (municipal) fixed effects as we have a large panel. Previous research with cost functions has shown the importance of including fixed effects [see Dijkgraaf and Gradus (2015)]. Moreover, Palatnik et al. (2014) show for the Netherlands that the combination of UBP with door-to-door recycling is associated with a $40 \%$ reduction in unsorted waste generation relative to a setting with only drop-off or limited door-to-door recycling or no UBP. Therefore, to investigate such interaction effects, we construct a variable combining UBP with the number of types of recyclables collected door-to-door and a variable combining

2 These are the most important households' waste streams in the Netherlands in terms of quantity (kg per inhabitant). Some municipalities collect metal such as aluminum beverage containers separately (e.g. packaging). However, as their quantity is very small, we will not discuss it here.

3 In many cases, the duo-bin is used simultaneously for unsorted waste and compostable waste. 
the existence of drop-off centers with curbside collection. We show that such multiplicative interaction effects are not present in our model.

The paper is organized as follows. In Sect. 2, data and method are discussed. Estimation results are given in Sect. 3 for recycling rates and in Sect. 4 for the interaction effects. Finally, Sect. 5 contains some conclusions.

\section{Method and Data}

Data on unit-based pricing and the amount of (household) waste and recyclables come from Netherlands Enterprise Agency. ${ }^{4}$ Total waste in the Netherlands is weekly approximately 12 kilogram (25 US pound) per household. We have data for 519 municipalities for the period 1998-2012, with a total of 5321 observations. ${ }^{5}$ Furthermore, Statistics Netherlands (CBS) collects yearly information on the number of times in a year curbside collection of (unsorted) waste takes place, the type of container that is used and whether there are other waste collection facilities in a municipality. ${ }^{6}$ That information is not available publicly but was sent to us upon request in July 2014. Data for the socio-economic characteristics come from CBS as well and they are available publicly. For descriptive statistics, see Table 1 (see "Appendix 1" for the variable definitions).

Similarly to Abbott et al. (2011), ${ }^{7}$ we model the local authority recycling rate as a function of socio-economic variables, unit-based pricing dummies, curbside frequency variables and dummies for nearby collection points, as follows:

$$
\begin{aligned}
R R_{i k t}= & \alpha_{0}+\beta_{1} \ln (H S)_{i t}+\beta_{2} \ln (P D)_{i t}+\beta_{3} \ln (E T)_{i t}+\beta_{4} \ln (Y)_{i t} \\
& +\sum_{j=1}^{o} \lambda_{j} D S I Z E_{j i t}+\sum_{l=1}^{n} \gamma_{j} U B P_{l i t}+\sum_{k=1}^{m} \theta_{k} F R_{k i t} \\
& +\sum_{\substack{1 \leq k \leq m \\
1 \leq s \leq d}} \emptyset(k, s) C R_{s k i t}+\vartheta_{D} V O L_{i t}+\omega_{i}+\pi_{t}+\varepsilon_{i k t},
\end{aligned}
$$

where $R R_{i k t}$ is the recycling rate of municipality $i$ for material $k$ at time $t, \ln (H S)$ is the $\log$ of average household size, $\ln (P D)$ is the $\log$ of population density, $\ln (E T)$ is ethnicity, defined as the $\log$ of the share of non-western people and $\ln (Y)$ is the $\log$ of income per inhabitant. $D S I Z E_{j}$ are dummies with value 1 if municipalities are of a certain size category $j$ (number of inhabitants under 20,000, between 20,000 and 50,000, between 50,000 and 100,000, and over 100,000), $U B P_{l}$ are dummies with value 1 for municipalities that use a unit-based pricing system of type $l$ (volume, frequency, bags and weight), $F R_{k}$ is a variable that denotes for the $k^{\text {th }}$ material the number of times in a year curbside collection takes place, $C R_{s k i}$ is a dummy that indicates for the $k^{\text {th }}$ material the container type $s$ (mini-bin, duo-bin, bag or

\footnotetext{
4 This data set does not contain information on user fee waste prices.

5 The number of Dutch municipalities decreased from 548 in 1998 to 415 in 2012. For 1998, data are available on $72 \%$ of the municipalities. Data availability is increasing over the years (in $201285 \%$ ). For some small municipalities data are only available in a couple of years. When several municipalities merge into a new municipality, we label this as a new observation.

6 It should be noted that this enquiry changed substantially in 2007 and therefore some variables are only available from 2007 onwards.

7 Abbott et al. (2011) argue that the theoretical literature does not suggest a particular specification as loglinear or double-log for the relationship between recycling and independent variables. Therefore, recycling performance can enter the model in a variety of ways: volume; participation rate in curbside scheme; or recycling rate. Similarly to Abbott et al. (2011), we choose the last of these since most policymakers evaluate the effectiveness of recycling and waste management programs by considering the recycling rate.
} 
Table 1 Descriptive statistics

\begin{tabular}{|c|c|c|c|c|c|}
\hline & Average & SD & Max. & Min. & Obs. \\
\hline Unsorted waste as share of total collected waste & 0.50 & 0.10 & 0.90 & 0.10 & 5321 \\
\hline Compostable waste as share of total collected waste & 0.25 & 0.08 & 0.55 & 0.00 & 5321 \\
\hline Paper waste as share of total collected waste & 0.18 & 0.05 & 0.47 & 0.00 & 5321 \\
\hline Glass waste as share of total collected waste & 0.05 & 0.02 & 0.20 & 0.00 & 5321 \\
\hline Textile waste as share of total collected waste & 0.01 & 0.01 & 0.08 & 0.00 & 5321 \\
\hline Plastic waste as share of total collected waste & 0.02 & 0.02 & 0.14 & 0.00 & 1972 \\
\hline Household size & 2.48 & 0.20 & 3.65 & 1.68 & 5321 \\
\hline Population density & 0.01 & 0.01 & 0.37 & 0.00 & 5321 \\
\hline Municipalities 20-50 & 0.40 & 0.49 & 1 & 0 & 5321 \\
\hline Municipalities 50-100 & 0.09 & 0.28 & 1 & 0 & 5321 \\
\hline Municipalities > 100 & 0.05 & 0.23 & 1 & 0 & 5321 \\
\hline Ethnicity & 0.05 & 0.04 & 0.37 & 0.00 & 5321 \\
\hline Income (thousand euro) & 30.55 & 4.14 & 54.87 & 5.08 & 5321 \\
\hline UBP: volume & 0.07 & 0.26 & 1 & 0 & 5321 \\
\hline UBP: frequency & 0.13 & 0.33 & 1 & 0 & 5321 \\
\hline UBP: bag & 0.04 & 0.20 & 1 & 0 & 5321 \\
\hline UBP: weight & 0.05 & 0.21 & 1 & 0 & 5321 \\
\hline UBP: volume, low recycling & 0.012 & 0.11 & 1 & 0 & 5321 \\
\hline UBP: frequency, low recycling & 0.019 & 0.14 & 1 & 0 & 5321 \\
\hline UPB: bag, low recycling & 0.002 & 0.05 & 1 & 0 & 5321 \\
\hline UBP: weight, low recycling & 0.001 & 0.03 & 1 & 0 & 5321 \\
\hline UBP and curbside & 1.01 & 1.68 & 6 & 0 & 5321 \\
\hline UBP: volume and curbside & 0.24 & 0.90 & 6 & 0 & 5321 \\
\hline UBP: frequency and curbside & 0.45 & 1.24 & 6 & 0 & 5321 \\
\hline UBP: bag and curbside & 0.15 & 0.72 & 5 & 0 & 5321 \\
\hline UBP: weight and curbside & 0.17 & 0.81 & 6 & 0 & 5321 \\
\hline Bring: paper (dum) & 0.74 & 0.44 & 1 & 0 & 5321 \\
\hline Bring: glass (dum) & 0.82 & 0.39 & 1 & 0 & 5321 \\
\hline Bring: textile (dum) & 0.84 & 0.37 & 1 & 0 & 5321 \\
\hline Frequency: unsorted & 30.36 & 10.14 & 52 & 4 & 1944 \\
\hline Frequency: compost & 29.79 & 10.89 & 52 & 0 & 5321 \\
\hline Frequency: paper & 14.91 & 11.21 & 52 & 0 & 5321 \\
\hline Frequency: glass & 2.17 & 8.63 & 52 & 0 & 5321 \\
\hline Frequency: textile & 5.70 & 9.24 & 52 & 0 & 5321 \\
\hline Frequency: plastic & 6.61 & 10.17 & 52 & 0 & 1944 \\
\hline Unsorted: duo-bin & 0.09 & 0.29 & 1 & 0 & 1944 \\
\hline Unsorted: mini-bin & 0.87 & 0.34 & 1 & 0 & 1944 \\
\hline Unsorted: bag & 0.12 & 0.32 & 1 & 0 & 1944 \\
\hline Compostable: duo-bin & 0.09 & 0.29 & 1 & 0 & 1944 \\
\hline Compostable: mini-bin & 0.91 & 0.29 & 1 & 0 & 1944 \\
\hline Compostable: bag & 0.02 & 0.15 & 1 & 0 & 1944 \\
\hline Compostable: crate & 0.01 & 0.10 & 1 & 0 & 1944 \\
\hline
\end{tabular}


Table 1 continued

\begin{tabular}{|c|c|c|c|c|c|}
\hline & Average & SD & Max. & Min. & Obs. \\
\hline Paper: duo-bin & 0.01 & 0.08 & 1 & 0 & 1944 \\
\hline Paper: mini-bin & 0.35 & 0.48 & 1 & 0 & 1944 \\
\hline Paper: bag & 0.03 & 0.16 & 1 & 0 & 1944 \\
\hline Paper: crate & 0.59 & 0.49 & 1 & 0 & 1944 \\
\hline Glass: duo-bin & 0.00 & 0.02 & 1 & 0 & 1944 \\
\hline Glass: mini-bin & 0.01 & 0.08 & 1 & 0 & 1944 \\
\hline Glass: crate & 0.04 & 0.20 & 1 & 0 & 1944 \\
\hline Textile: duo-bin & 0.00 & 0.02 & 1 & 0 & 1944 \\
\hline Textile: mini-bin & 0.05 & 0.22 & 1 & 0 & 1944 \\
\hline Textile: bag & 0.57 & 0.50 & 1 & 0 & 1944 \\
\hline Textile: crate & 0.10 & 0.30 & 1 & 0 & 1944 \\
\hline Plastic: duo-bin & 0.00 & 0.06 & 1 & 0 & 1944 \\
\hline Plastic: mini-bin & 0.05 & 0.22 & 1 & 0 & 1944 \\
\hline Plastic: bag & 0.30 & 0.46 & 1 & 0 & 1944 \\
\hline Plastic: crate & 0.03 & 0.17 & 1 & 0 & 1944 \\
\hline Volunteer & 0.85 & 0.36 & 1 & 0 & 1944 \\
\hline
\end{tabular}

Unsorted waste is not collected in crates and glass is not collected in bags

crate) and $D V O L$ is a dummy with value 1 if volunteer organization(s) collect paper in a municipality. Finally, $\omega_{i}$ are municipal fixed effects ${ }^{8}, \pi_{t}$ are year fixed effects and $\varepsilon_{i k t}$ is the normally distributed error term.

For 1998-2012, the recycling rate as a percentage of total (household) waste is constructed separately for unsorted waste, glass, textiles, paper and compostable waste. As we only have data for plastics from 2007 onwards, the plastics recycling rate is constructed for 20072012. The same subsample is used for the container type variable, as data before 2007 are not available.

While the Dutch recycling rates are more or less stable over time with the exception of plastics at the end of the period (see Fig. 1), there is significant variation between municipalities. In Fig. 2, we present the 1998 and 2012 shares of recycled waste in total waste for each municipality, with the municipalities counted on the horizontal axis. The graph shows that there are some municipalities that recycle more than $65 \%$ and also a few that recycle less than 30\%. ${ }^{9}$ On average, Dutch municipalities recycled $50 \%$ of their waste in 1998 and $48 \%$ in 2012 . However, the number of municipalities with a recycling rate over $65 \%$ is still small, only 23 in 2012.

Dutch municipalities may choose how materials such as paper, glass, textiles and plastics are collected. If they are not collected at the curbside, citizens can deliver them to collection points at central locations nearby, such as shopping centers and schools. Unsorted waste is collected at the curbside in all municipalities. Paper is collected at the curbside in $89 \%$ of

8 These fixed effects will in general capture some features on which we have no information on a municipal level.

9 Due to mergers, the number of municipalities decreased between 1998 and 2012. The number of municipalities with a recycling rate under $65 \%$ was 373 (95\%) in 1998 and 321 (94\%) in 2012. 


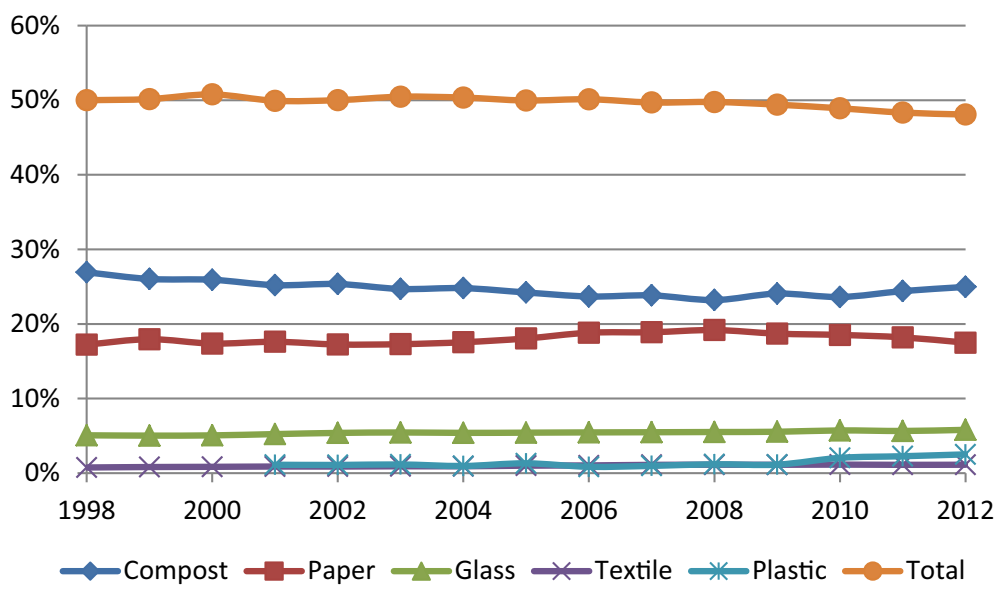

Fig. 1 Average municipal recycling rates (\% of total waste)

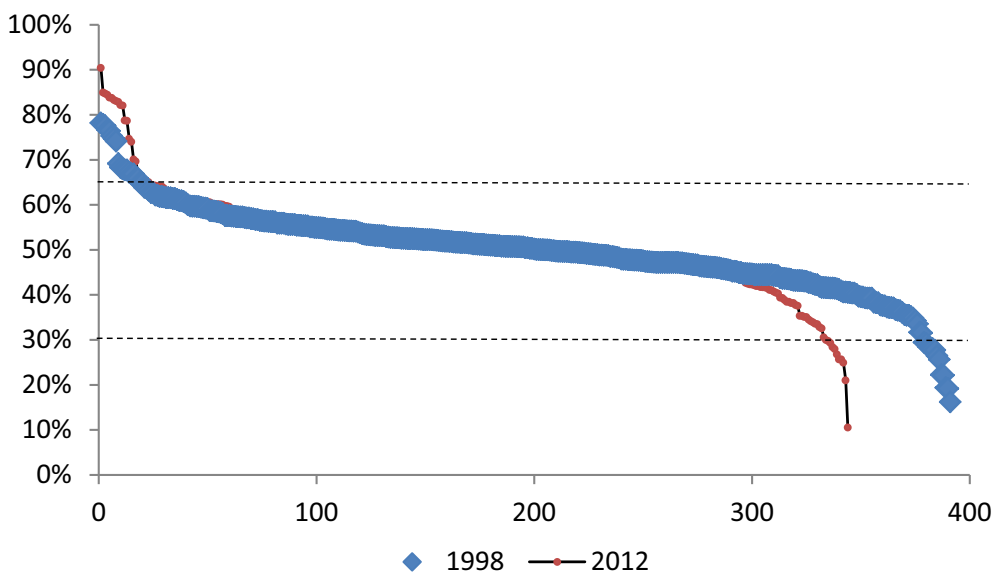

Fig. 2 Recycling rate by municipality (\% of total waste on y-axis and municipalities sorted at level of recycling on $\mathrm{x}$-axis)

municipalities; for plastics, this figure is $37 \% .{ }^{10}$ Interestingly, in $85 \%$ of Dutch municipalities, the curbside program for paper is organized by local associations such as sports clubs and schools. ${ }^{11}$ There is a large difference between the frequency of collecting unsorted and compostable waste and the frequency for different recyclables (see Fig. 3). Most municipalities collect unsorted and compostable waste every 2 weeks. For compostable waste, $81 \%$ of the municipalities collect it every 2 weeks (24-27 times a year), while $16 \%$ collect it every week ( $\geq 52$ times a year). These figures are 81 and $18 \%$ for unsorted waste. Most municipalities with curbside collection collect paper and plastics once each month (or every 4 weeks). For

\footnotetext{
10 For compostable waste, curbside collection takes place at $97 \%$ of all Dutch municipalities. It should be noted that although curbside collection of compostable waste is obliged by law, some municipalities get exemptions from collecting compostable waste for large parts of their city as there are many flats (for example, Amsterdam).

11 We do not have information about whether this is cost-effective for municipalities; they save money due to lower collection costs, but the associations also get part of the recycling revenues.
} 


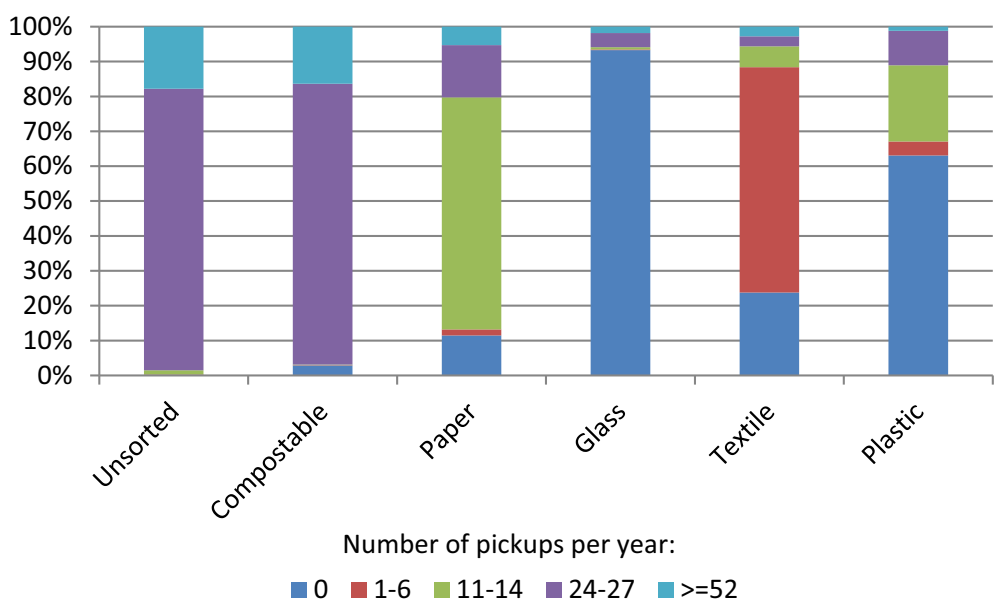

Fig. 3 Distribution of curbside frequency for each type of collected waste, all municipalities, 1998-2012, Number of pickups per year: Note: For unsorted waste and plastics, we only have data from 2007 onwards

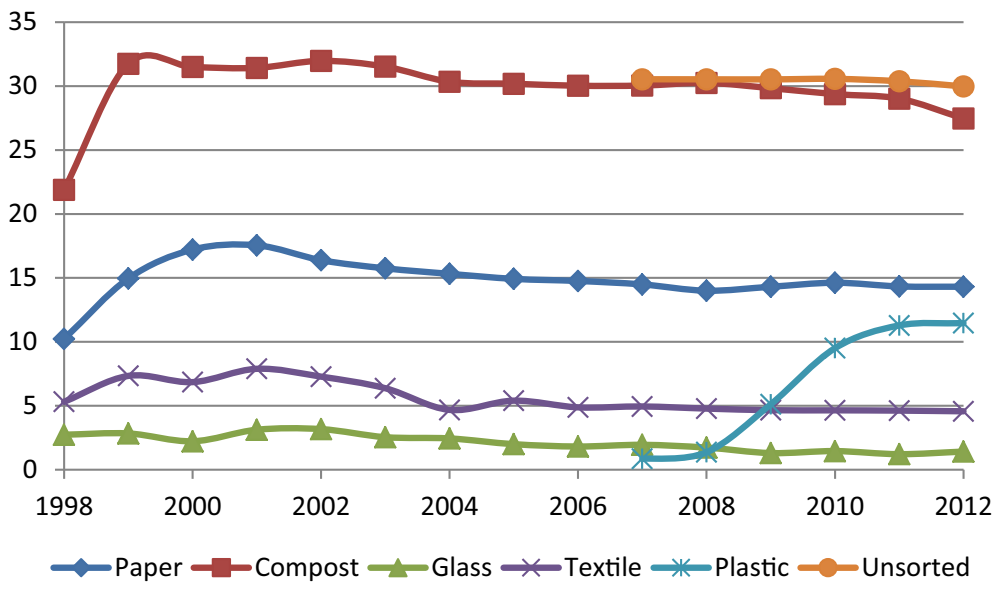

Fig. 4 Curbside frequency in number of pickups per year, Note: For unsorted waste and plastics, we only have data from 2007 onwards

paper, $67 \%$ of municipalities collect once a month (11-14 times a year), while $15 \%$ collect twice a month (24-27 times a year) and 5\% collect each week. Glass is collected at the curbside to a lesser extent. Of all municipalities, $7 \%$ collect glass at the curbside. Curbside collection is more common for textiles $(76 \%)$, but most municipalities $(65 \%)$ collect them every quarter (1-6 times a year). Plastics are collected at the curbside in $37 \%$ of municipalities. Over half of these municipalities (59\%) collect them once a month and a quarter $(27 \%)$ twice a month.

Figure 4 shows the number of pickups at the curbside on average for all municipalities. For most waste streams, the frequency declines over time. The exceptions are the first few years for compostable waste, paper and textiles and the last few years for plastics. 
The type of container differs considerably between materials. Most municipalities collect unsorted waste from a mini-bin of $60,120,140$ or $2401(87 \%) .{ }^{12}$ Other municipalities collect it from a duo-bin $(9 \%)$ or a bag $(12 \%) .{ }^{13}$ For compostable waste, a bin of 120, 140 or 2401 is dominant, at $91 \% ;{ }^{14}$ duo-bins $(9 \%)$, bags $(2 \%)$ and crates $(1 \%)$ are also used. A crate or box is dominant for paper $(59 \%) .{ }^{15}$ Paper is also collected from a mini-bin (35\%), a duo-bin $(1 \%)$ or a bag $(3 \%)$. For glass curbside collections, a mini-bin (1\%) or a crate $(4 \%)$ is used. Most glass is collected via drop-off facilities. For textiles, a bag is dominant (57\%). ${ }^{16}$ Textile collections are also made from a mini-bin $(5 \%)$ or a crate $(10 \%)$. Finally, for plastics, a bag is the most important $(30 \%)$. Other containers for plastics are mini-bins $(5 \%)$ and crates $(3 \%)$.

The way citizens pay for waste collection differs by municipality. In most Dutch municipalities, ranging from $85 \%$ in 1998 to $63 \%$ in 2012, a flat-rate system has been used. In other municipalities, unit-based pricing is used for unsorted and/or compostable waste. This introduces a price that provides an incentive to reduce the quantity of waste and to sort the waste better. Thus, with UBP, it is expected that municipalities collect less priced waste and more unpriced recyclable waste. As in Dijkgraaf and Gradus (2004, 2015), we distinguish between four different UBP systems: volume, frequency, bag and weight. ${ }^{17}$ The volumebased program allows households to choose between different volumes of collection bins for unsorted and/or compostable waste; on average between 1998 and 2012, $7 \%$ of Dutch municipalities used this rather crude UBP system. ${ }^{18}$ It is rather crude as the price is on a yearly basis. A more refined marginal price results from a frequency-based system, in which the household pays for the number of times the bin for unsorted and compostable waste is presented at the curbside. ${ }^{19}$ The share of municipalities using this system increased from $4 \%$ in 1998 to $19 \%$ in 2012 (on average 13\%) and we argue in Dijkgraaf and Gradus (2015) that this increase in popularity is due to the low administrative costs. In the bag-based system, households buy a special bag with specific marks. This is a more refined pricing system than the frequency-based one, as the volume of the bags is significantly less than that of the bins. Importantly, the bag system allows households to change volume each week. The share of municipalities with such a system is stable, at 4\% in 1998 and 2012. Maximum price incentives result from a weight-based system, pricing the unsorted and compostable waste per kilogram. The collection vehicle weighs the bin before emptying and combines this information with the identity of the owner, stored in a chip integrated in the collection bin. Use of the more refined weight-based system increased at the beginning of this century and, due to large administrative costs, stabilized after 2005 at $5 \%$.

\footnotetext{
12 Our data set does not contain information on the size of the container.

13 In some municipalities, more than one system is used; thus the sum of the shares is greater than $100 \%$.

14 Our data set does not contain information on the size of the container.

15 Our data set does not contain information about the size of this crate. In some municipalities, it measures $45 \times 28 \times 20$ centimeters and these crates are distributed by the municipality. In some municipalities, cardboard boxes (for example, coming from shop purchases) are allowed to be used.

16 In some municipalities, these sacks are labeled or have a special color.

17 Some municipalities use a combination of these systems. We count these under the most refined system.

18 Changes during a year in waste supply behavior does not influence the yearly bill. Most municipalities supply a standard bin with a volume of 1401, with the possibility of upgrading to a 240-litre bin or of subscribing to more 140-litre bins with a higher tariff as a result.

19 Some municipalities combine this frequency-based system with a volume system, where households have to pay special tariffs for different bins at the curbside. These combinations are counted as the frequency system.
} 
Table 2 Estimated models without type of container (1998-2012)

\begin{tabular}{|c|c|c|c|c|c|}
\hline & Unsorted (\%) & Paper $(\%)$ & Compost $(\%)$ & Glass (\%) & Textile (\%) \\
\hline Household size & -0.0244 & 0.0042 & $0.0815^{* *}$ & -0.0119 & $-0.0144 * * *$ \\
\hline Population density & -0.0159 & 0.0030 & 0.0157 & -0.0042 & 0.0013 \\
\hline Municipalities 20-50 & -0.0011 & 0.0017 & 0.0017 & 0.0010 & -0.0023 \\
\hline Municipalities 50-100 & 0.0166 & 0.0014 & -0.0128 & -0.0011 & -0.0023 \\
\hline Municipalities $>100$ & -0.0289 & 0.0081 & 0.0053 & 0.0042 & 0.0009 \\
\hline Ethnicity & $0.0141^{* *}$ & -0.0002 & $-0.0115^{*}$ & 0.0003 & -0.0009 \\
\hline Income & -0.0155 & 0.0080 & 0.0042 & 0.0051 & $0.0041 *$ \\
\hline UBP: volume & $-0.0225^{* * *}$ & $0.0107 * * *$ & $0.0104 * *$ & 0.0018 & 0.0002 \\
\hline UBP: frequency & $-0.0241 * * *$ & $0.0491 * * *$ & $-0.0530 * * *$ & $0.0165 * * *$ & $0.0022 * * *$ \\
\hline UBP: bag & $-0.1431 * * *$ & $0.0320 * * *$ & $0.0836 * * *$ & $0.0140 * * *$ & $0.0028 *$ \\
\hline UBP: weight & $-0.0509 * * *$ & $0.0989 * * *$ & $-0.1042^{* * *}$ & $0.0303 * * *$ & $0.0041^{* *}$ \\
\hline Frequency: paper & $-0.0002 *$ & $0.0001 *$ & 0.0001 & 0.0000 & 0.0000 \\
\hline Frequency: compost & $0.0004 * * *$ & 0.0000 & $-0.0004 * * *$ & 0.0000 & $0.0000 *$ \\
\hline Frequency: glass & $-0.0002 *$ & 0.0001 & -0.0001 & $0.0001 * *$ & 0.0000 \\
\hline Frequency: textile & $-0.0002 * *$ & 0.0000 & 0.0001 & 0.0000 & 0.0000 \\
\hline $\mathrm{R}^{2}$ & 0.51 & 0.56 & 0.44 & 0.43 & 0.07 \\
\hline Observations & 5321 & 5321 & 5321 & 5321 & 5321 \\
\hline
\end{tabular}

***; **; *Significance at the 99\%; $95 \%$; $90 \%$ level. Models estimated with municipal and year fixed effects

\section{Results: Recycling Rates}

We follow Kinnaman and Fullerton (2000) and estimate the material-specific recycling rates as a series of demand equations. Since the independent variables in each equation are the same, there is no bias from estimating the system as separate equations. First, we estimate Eq. (1) for the full sample (1998-2012) and we have to omit container type, volunteer and the frequency for unsorted waste and plastics. Second, for the period 2007-2012, we can estimate all the coefficients in Eq. (1). Tables 2 and 3 show the estimation results for the recycling rate functions (including the plastics recycling rate in Table 3). All estimations are based on pooled ordinary least squares (OLS) with standard errors clustered by municipality. ${ }^{20}$

In the literature, there has been some discussion about the endogeneity of the UBP variables [see Usui and Takeuchi (2013) and Dijkgraaf and Gradus (2015)]. Because of the unavailability of appropriate instrumental variables (IV) in such analysis, Usui and Takeuchi (2013) and Dijkgraaf and Gradus (2015) deal with the possible endogeneity of the UBP variables by considering the bias caused by any omitted variable such as environmental activism, a lagged variable for announcement effects and elements of the recycling policy. They concluded that any bias that might be caused is not serious. In "Appendix 2" we also investigate this for the model in (1) and draw the same conclusions.

20 It will be assumed that the standard errors for each municipality are not independently and identically distributed, that there is unknown correlation in $\varepsilon_{i t}$ between the same municipality, but that municipality $i$ and $j$ do not have correlated errors [see Nichols and Schaffer (2007)]. 
Table 3 Estimated models with type of container (2007-2012)

\begin{tabular}{|c|c|c|c|c|c|c|}
\hline & Unsorted (\%) & Paper $(\%)$ & Compost (\%) & Glass (\%) & Textile $(\%)$ & Plastic (\%) \\
\hline Household size & -0.0763 & 0.0403 & $0.2529 * *$ & -0.0160 & -0.0010 & $-0.1271 * * *$ \\
\hline Population density & -0.0165 & 0.0023 & 0.0162 & -0.0067 & $-0.0087 * *$ & 0.0139 \\
\hline Municipalities 20-50 & -0.0135 & $-0.0128 * *$ & 0.0186 & 0.0023 & $0.0027 * *$ & 0.0003 \\
\hline Municipalities 50-100 & -0.0197 & -0.0011 & 0.0082 & 0.0013 & $0.0041 * *$ & 0.0022 \\
\hline Municipalities > 100 & -0.0224 & -0.0045 & 0.0158 & -0.0005 & $0.0083 * * *$ & -0.0027 \\
\hline Ethnicity & $0.0203 *$ & -0.0092 & -0.0062 & $-0.0053^{* *}$ & 0.0000 & -0.0004 \\
\hline Income & -0.0476 & $-0.0694 * *$ & $0.0965 * *$ & -0.0006 & 0.0059 & $0.0461 * *$ \\
\hline UBP: volume & $-0.0293 * * *$ & $0.0141 * * *$ & $0.0198 * * *$ & 0.0008 & -0.0002 & $-0.0106 * *$ \\
\hline UBP: frequency & $-0.0362 * * *$ & $0.0454 * * *$ & $-0.0388 * * *$ & $0.0139 * * *$ & $0.0024 * *$ & $0.0174 * * *$ \\
\hline UBP: bag & $-0.2406 * *$ & $0.1032 * * *$ & 0.0702 & $0.0358 * * *$ & $0.0063 * * *$ & $0.0732 * * *$ \\
\hline UBP: weight & $-0.0852 * * *$ & $0.0990 * * *$ & $-0.0864 * * *$ & $0.0295 * * *$ & $0.0065^{* * *}$ & $0.0384 * * *$ \\
\hline Frequency: unsorted & $0.0005^{*} *$ & 0.0001 & $-0.0007 * * *$ & 0.0000 & 0.0000 & 0.0001 \\
\hline Frequency: paper & -0.0002 & 0.0001 & 0.0001 & 0.0000 & 0.0000 & 0.0000 \\
\hline Frequency: compost & $0.0002 *$ & 0.0000 & -0.0001 & 0.0000 & 0.0000 & 0.0000 \\
\hline Frequency: glass & 0.0000 & 0.0000 & -0.0001 & 0.0000 & 0.0000 & $0.0001 *$ \\
\hline Frequency: textile & 0.0000 & 0.0000 & 0.0000 & $-0.0001 * *$ & 0.0000 & 0.0000 \\
\hline Frequency: plastic & 0.0001 & 0.0000 & $-0.0002 * *$ & 0.0000 & 0.0000 & 0.0000 \\
\hline Unsorted: duo-bin & $-0.0910 * *$ & $0.0270 * *$ & 0.0397 & $0.0114 * *$ & $0.0032 * *$ & 0.0026 \\
\hline Unsorted: mini-bin & -0.0095 & $0.0149 *$ & 0.0025 & -0.0029 & 0.0008 & -0.0065 \\
\hline Unsorted: bag & -0.0079 & -0.0054 & $0.0153 * * *$ & 0.0004 & -0.0001 & -0.0031 \\
\hline Compost: duo-bin & $0.1293 * * *$ & $-0.0277 * *$ & $-0.0671^{* *}$ & $-0.0087^{* *}$ & $-0.0032 * *$ & $-0.0112 * * *$ \\
\hline Compost: mini-bin & 0.0144 & -0.0109 & -0.0006 & 0.0048 & 0.0007 & -0.0017 \\
\hline Compost: bag & -0.0085 & 0.0041 & 0.0022 & 0.0014 & 0.0000 & -0.0004 \\
\hline Compost: crate & 0.0088 & 0.0020 & -0.0040 & -0.0042 & 0.0003 & 0.0014 \\
\hline Paper: duo-bin & -0.0146 & 0.0071 & $0.0119 *$ & 0.0010 & $0.0019 *$ & $-0.0109 *$ \\
\hline Paper: mini-bin & -0.0027 & 0.0023 & 0.0019 & -0.0004 & 0.0000 & -0.0011 \\
\hline Paper: bag & -0.0028 & -0.0002 & 0.0002 & -0.0007 & 0.0014 & -0.0014 \\
\hline Paper: crate & 0.0045 & -0.0012 & -0.0036 & 0.0001 & 0.0004 & 0.0000 \\
\hline Glass: duo-bin & 0.0039 & $0.0653 * * *$ & $-0.0538 * * *$ & $-0.0079 * * *$ & $0.0053 * * *$ & - \\
\hline Glass: mini-bin & -0.0131 & 0.0147 & -0.0119 & 0.0015 & -0.0019 & -0.0026 \\
\hline Glass: crate & 0.0111 & -0.0008 & $-0.0088^{*}$ & 0.0008 & -0.0009 & $-0.0199 * *$ \\
\hline Textile: duo-bin & -0.0061 & $-0.0172 *$ & $0.0214 * * *$ & 0.0027 & -0.0006 & - \\
\hline Textile: mini-bin & -0.0011 & 0.0016 & -0.0024 & -0.0004 & $0.0012 * * *$ & 0.0013 \\
\hline Textile: bag & -0.0021 & 0.0004 & 0.0024 & -0.0001 & 0.0004 & 0.0009 \\
\hline Textile: crate & -0.0007 & 0.0019 & -0.0026 & 0.0005 & 0.0003 & $0.0030 * *$ \\
\hline Plastic: duo-bin & 0.0175 & -0.0055 & -0.0189 & -0.0060 & -0.0006 & $0.0233 * * *$ \\
\hline Plastic: mini-bin & $-0.0143 * * *$ & -0.0009 & 0.0046 & 0.0005 & 0.0003 & $0.0096^{* * *}$ \\
\hline Plastic: bag & $-0.0116^{* * *}$ & -0.0007 & 0.0007 & 0.0003 & $0.0005^{*}$ & $0.0087 * * *$ \\
\hline Plastic: crate & -0.0039 & -0.0016 & 0.0030 & -0.0007 & 0.0002 & 0.0016 \\
\hline
\end{tabular}


Table 3 continued

\begin{tabular}{lllllll}
\hline & Unsorted $(\%)$ & Paper $(\%)$ & Compost $(\%)$ & Glass $(\%)$ & Textile $(\%)$ & Plastic $(\%)$ \\
\hline Volunteer & 0.0004 & $0.0049^{* * *}$ & -0.0039 & 0.0006 & 0.0000 & -0.0026 \\
$\mathrm{R}^{2}$ & 0.54 & 0.57 & 0.37 & 0.43 & 0.01 & 0.29 \\
Observations & 1972 & 1972 & 1972 & 1972 & 1972 & 1165 \\
\hline
\end{tabular}

***; **; * Significance at the 99\%; 95\%; $90 \%$ level. Models estimated with municipal and year fixed effects. "_" means coefficient not estimated due to singularity

Unit-based pricing systems are effective in reducing unsorted waste and stimulating recyclable waste [see also Dijkgraaf and Gradus $(2004,2014)$ and Allers and Hoeben (2010)]. ${ }^{21}$ For the paper, glass, textile and plastic recycling rates, nearly all the UBP coefficients are significant and positive. In particular, the bag-based system is effective in reducing the unsorted waste rate. From Table 2 it follows that the reduction from having such a system is $14.3 \%$ points (the reduction is even larger in Table 3 , at $24.1 \%$ points $^{22}$ ). However, disadvantages of the bag-based system for the Netherlands are that Dutch legislation limits the number of bags carried per waste-collection employee and that there is an incentive for households to put as much waste as possible in each bag, which might makes them difficult to handle. ${ }^{23}$ Furthermore, it should be noted that a policy of introducing bags does not stimulate home composting given the current data gathering. Home composting lowers the (measured) recycling rate as it is not included in the official statistics. Finally, for some Dutch (coastal) municipalities, there are indications that bags have another disadvantage, as birds such as gulls will cause extra nuisance by picking over bags. ${ }^{24}$

For the weight-based and frequency-based pricing systems, the disadvantages of the bag system are not present and in most cases there are sizeable reductions in the unsorted waste rate as well, although the effects of these policies are not larger than $9 \%$ points. The introduction of these unit-based pricing systems may, however, have adverse effects as well. In particular, the weight system has large administrative costs and citizens may take their waste to neighboring municipalities without UBP. However, Allers and Hoeben (2010) show that there is no evidence that surrounding municipalities without unit-based pricing systems in fact collect part of the waste produced in Dutch municipalities that do have them. Also according to Allers and Hoeben (2010) illegal dumping is not a serious problem in the Netherlands, as one would expect that many municipalities would have abolished user fees if this were the case and this has not happened (substantially). ${ }^{25}$

21 In Dijkgraaf and Gradus (2004, 2014) and Allers and Hoeben (2010), the effects of Dutch unit-based pricing on total waste, unsorted waste, (total) recyclable waste and compostable waste are estimated. In Dijkgraaf and Gradus (2015), the effect of unit-based pricing systems on costs is estimated.

22 An explanation for this is that nowadays the bag-based system is generally used for unsorted waste only. Also, Allers and Hoeben (2010) show that the number of municipalities pricing compostable waste dropped markedly between 1997 and 2006. This point is also illustrated by Tables 2 and 3, which shows that the use of a bag-based system leads to an increase in compostable waste.

23 It could be argued that governments could introduce a bag weight limit, but in the Netherlands we have no indication for such limits. Probably, because this would create nuisance in the public space.

24 In some cities as the Hague and Leiden some special policies have been announced to deal with these gulls.

25 In other countries, there is some evidence that illegal dumping is an important issue. Fullerton and Kinnaman (1996) estimate that for a unit-based pricing system in Charlottesville (VA, USA), illegal dumping constitutes $28 \%$ of the total reduction in waste collected at the curb. Miranda and Aldy (1998) show for the US that this can be limited remarkably with the strict enforcement of anti-dumping measures. 
In terms of the socio-economic variables, we find that most of them have poor explanatory power. The income coefficient is only significant (at 95\%) for 2007-2012 for paper, plastics and compostable waste - the first negative and two others positive. According to Abbott et al. (2011), two opposing effects are working here. Higher earners have a higher propensity to recycle, because caring for the environment is a luxury good, but they also have a higher opportunity cost of time, which acts to reduce their recycling rates. For compostable waste, it is to be expected that higher-income municipalities have more houses with bigger yards and thus more compostable waste to recycle. Furthermore, there is some evidence that plastic packaging is related to luxury products and therefore with income. Paper is far less income-sensitive, making it explainable that the effect is different. The estimated coefficient for population density is only significant and negative for textiles in the period $2007-2012 .{ }^{26}$ In the compost equation, the coefficient for household size is significant and positively signed. A possible reason for this result is that larger households tend to live in larger properties-for example, detached housing with bigger garden space and hence more opportunity for composting. In the textiles equation for the full panel, the coefficient for household size is significant and negatively signed. A possible explanation for this is that larger households have more opportunity to transfer clothes within the household. We also find a negative effect in the plastics equation. It could be that larger family size results in higher opportunity costs of time due to increasing scarcity of time as more time is spent on the family. Based on our results, non-western ethnic groups recycle less glass and compostable waste, although the latter result is only significant at the $90 \%$ level. This is line with Abbott et al. (2013, 2014), who found that western ethnic groups have a stronger social norm to recycle. ${ }^{27}$ For unsorted waste the dummies for municipality size (expect one) are, as we would expect, negative; however, they are not significant. Interestingly, we find a positive relation between municipality size and textile recycling in the 2007-2012 panel but not in the full panel. An explanation for this can be found in the increase in the number of thrift shops in large municipalities after the crisis [see Groenewold and Spronk (2012)].

Intuitively, we would expect a (strong) positive relationship between the frequency of collection and the quantity of collected material. For glass and paper (in the full panel) and for unsorted waste (in the 2007-2012 panel), we find a positive and significant result, but the coefficients are small. If instead of every 2 weeks unsorted waste is collected once a week, the unsorted waste rate increases by $1.3 \%$ points. For glass and paper, the effect is even smaller with $0.5 \%$ points. Surprisingly, if the compost collection frequency increases, the consequence in the full panel is a decrease in the compost recycling rate. Abbott et al. (2011) argue that the nature of the composting activity is such that it takes place on a much more infrequent basis and in general the collection will not match the compost production of households.

Turning to the cross-frequency effects, two cross-effects are significant at the $95 \%$ level in the full panel and three in 2007-2012 panel. But even in these cases, the coefficients are very small. Interestingly, and also in line with Abbott et al. (2011), we find that a decrease in frequency of the unsorted waste collection increases the recycling rate for compostable waste. The intuition behind this result is that when faced with fewer unsorted waste collections, households have an incentive to exert more effort in separating compostable waste from

\footnotetext{
26 Callan and Thomas (1997) and Kinnaman and Fullerton (2000) also find a significant and negative relationship between population density and recycling.

27 Abbott et al. $(2013,2014)$ examine the role of social norms in general. Based on English local authority data, they show that a social norm for recycling exists. In their empirical investigation, the social norm is defined using (1) the age profile of the authority (aged 65 or older), (2) the ethnic profile (proportion that is white) and (3) the educational attainment (higher education). In all three cases, the estimates for social norms are positively correlated with the recycling rate and the variable is shown to be statistically significant as well.
} 
unsorted waste. By its nature, compostable waste is bulky and organic (leading to rotting and smells) and both stimulate the desirability of separate and outdoor storage.

We also get some interesting results for the type of container, especially for the duo-bin for unsorted and compostable waste. ${ }^{28}$ The effects of this duo-bin are $3.8 \%$ points more unsorted waste and $2.7 \%$ points less compostable waste. It seems that also here behavioral aspects play a role, as this duo-container is experienced as awkward and thus does not make the separation of unsorted and compostable waste appealing. If the compostable waste part of the duo-bin is too small, it will not fit the amount of compost produced in the summer. ${ }^{29}$ Interestingly, a separate bag or a bin for plastics increases the amount of plastic recycled and therefore decreases the unsorted waste rate significantly with more than 1 other container types, no clear pattern arises. With a glass duo-bin and a textiles duo-bin, we get some significant results for other recyclables, but it should be noted that the number of observations is very small (see Table 1). Finally, in municipalities where volunteers collect paper door-to-door, the paper recycling rate is $0.5 \%$ points higher.

\section{Results: Interaction Effects}

Introducing a unit-based pricing system has clearly a significant negative effect on the unsorted waste rate according to the evidence presented in Sect. 2. From Table 2 in the full panel, it can be seen that the bag system has the largest effect with $14.3 \%$ points followed by the weight system ( $5 \%$ point) and frequency system ( $2.5 \%$ point). In this paragraph, we explore these effects by adding two additional (interaction) variables. First, we investigate whether UBP plans have varying marginal effects or with other words as recycling rate increases, become these UBP policies less effective at the margin? Therefore, in the full panel, we add in Eq. (1) an extra UBPLR variable with value 1 if the municipality in case has less recycling than the average municipality in $1998 .{ }^{30}$ We would expect that introducing a UBP plan in such a case causes a larger decrease of unsorted waste and increase of recyclables. Table 4 contains the results.

For unsorted waste we find negative LR coefficients for all UBP systems, although the coefficient is only significant at $90 \%$ for the volume and bag based system. Importantly, the effect on unsorted waste of introducing a frequency or weight-based system is significantly larger. In case of low recycling rates, introducing a weight system has a total reducing effect on unsorted waste rate of $11.2 \%$ point and for the frequency system of $4.5 \%$ point. ${ }^{31} \mathrm{In}$ Dijkgraaf and Gradus (2015) we show that especially the number of Dutch municipalities with a frequency-based system has risen between 1998 and 2014 as their administrative costs are low and they can be effective for stimulating recycling especially if recycling is low. This result does not mean that for high recycling municipalities the UBP policies become less effective as the found effects for high recycling municipalities in Table 4 are still comparable with the model in Table 2.

\footnotetext{
28 Most municipalities use a duo-bin simultaneously for unsorted and compostable waste. The correlation coefficients for the independent variables are available on reques. There is almost a perfect correlation (i.e. 0.98) between a duo-bin for unsorted waste and a duo-bin for compostable waste. Therefore, the effect of a duo-bin is the combination of both coefficients (for duo-bin unsorted and duo-bin compostable waste) in Table 3.

29 The sizes of a mini-bin (normally 140 or 2401$)$ and a duo-bin $(2 \times 601$ or a maximum of 1201$)$ could be a factor. Unfortunately, we have no data to check This.

30 We thank an unanimous referee For this suggestion.

31 This is the sum of the UBP coefficient and UBPLR coefficient in Table 4.
} 
Table 4 Estimated models with extra variable for low recycling (1998-2012)

\begin{tabular}{|c|c|c|c|c|c|}
\hline & Unsorted (\%) & Paper $(\%)$ & GFT $(\%)$ & Glass $(\%)$ & Textile $(\%)$ \\
\hline Household size & -0.0223 & 0.0050 & $0.0801 * *$ & -0.0100 & $-0.0154 * * *$ \\
\hline Population density & -0.0119 & 0.0021 & 0.0127 & -0.0043 & 0.0013 \\
\hline Municipalities 20-50 & -0.0002 & 0.0020 & 0.0008 & 0.0006 & -0.0024 \\
\hline Municipalities 50-100 & 0.0159 & 0.0022 & -0.0127 & -0.0016 & -0.0023 \\
\hline Municipalities > 100 & -0.0308 & 0.0092 & 0.0062 & 0.0037 & 0.0009 \\
\hline Ethnicity & $0.0129 *$ & 0.0001 & $-0.0110^{*}$ & 0.0001 & -0.0009 \\
\hline Income & -0.0133 & 0.0069 & 0.0031 & 0.0046 & $0.0044 *$ \\
\hline UBP: volume & $-0.0143^{*}$ & $0.0106^{*}$ & 0.0035 & 0.0006 & -0.0002 \\
\hline UBP: frequency & $-0.0140 * *$ & $0.0454 * * *$ & $-0.0590 * * *$ & $0.0167 * * *$ & $0.0024 * * *$ \\
\hline UPB: bag & $-0.1346^{* * * *}$ & $0.0282 * *$ & $0.0814 * * *$ & $0.0123 * * *$ & $0.0035^{* *}$ \\
\hline UBP: weight & $-0.0440 * * *$ & $0.0968 * * *$ & $-0.1064 * * *$ & $0.0308 * * *$ & $0.0038 *$ \\
\hline UBPLR: volume & $-0.0210^{*}$ & -0.0014 & $0.0188 * *$ & 0.0037 & 0.0013 \\
\hline UBPLR: frequency & $-0.0312 * * *$ & 0.0120 & 0.0182 & -0.0012 & -0.0007 \\
\hline UPBLR: bag & $-0.0484^{*}$ & $0.0276^{* *}$ & 0.0055 & $0.0135 * * *$ & $-0.0067 * * *$ \\
\hline UBPLR: weight & $-0.0677 * * *$ & 0.0180 & 0.0202 & $-0.0077^{* *}$ & $0.0048 * *$ \\
\hline Frequency: paper & $-0.0002 * *$ & $0.0001^{*}$ & $0.0001 *$ & 0.0000 & 0.0000 \\
\hline Frequency: GFT & $0.0004 * * *$ & 0.0000 & $-0.0004 * * *$ & 0.0000 & $0.0000^{*}$ \\
\hline Frequency: glass & -0.0002 & 0.0000 & -0.0001 & $0.0001 * *$ & 0.0000 \\
\hline Frequency: textile & $-0.0001^{*}$ & 0.0000 & 0.0001 & 0.0000 & 0.0000 \\
\hline $\mathrm{R}^{2}$ & 0.47 & 0.53 & 0.43 & 0.43 & 0.08 \\
\hline Observations & 5321 & 5321 & 5321 & 5321 & 5321 \\
\hline
\end{tabular}

***; **; * Significance at the $99 \% ; 95 \% ; 90 \%$ level. Models estimated with municipal and year fixed effects

Second, we investigate interaction effects further by analyzing the effectiveness of UBP policies under different curbside recycling policies. Based on household survey for 2011, Palatnik et al. (2014) investigate the complementarities between unit-based waste pricing and the expansion of recycling services for 11 OECD countries. They construct a variable for service level with three levels and test its interaction with the existence of a unit-based pricing system. Moreover, they show that for the Netherlands, Canada, Sweden and Switzerland increasing recycling services from a medium to a high level is associated with $26 \%$ and $31 \%$ less waste, depending on whether or not UBP is present. ${ }^{32}$

Similarly to Palatnik et al. (2014), we construct a variable UBPcurbside and we add this variable to Eq. (1). It has value 0 if there is no curbside collection, 1 if there is a UBP system and curbside collection for one material, 2 if there is UBP and curbside collection for two materials, etc. We also construct a variable $U B P_{j}$ curbside, which gives the number of types of recyclables collected if a specific unit-based pricing system is introduced (i.e. volume, frequency, bag or weight). We estimate Eq. (1) again adding the variable $U B P_{j}$ curbside instead of UBPcurbside.

We find rather small coefficients for all UBPcurbside. In general, the effect of this interaction variable on unsorted waste rate is $-0.5 \%$ point (see Table 5) and if we distinguish between different UBP systems, the effect is always smaller than $1 \%$ point (see Table 5). For

\footnotetext{
${ }^{32}$ Low-level service is defined as drop-off services available for only some materials (plastics, paper, metal or glass); medium-level service is defined as drop-off services available for all of these materials and/or some door-to-door collection; and high-level service is defined as a door-to-door collection for all four materials.
} 
Table 5 Estimated models with general interaction curbside and (a) UBP and (b) $\mathrm{UBP}_{j}$

\begin{tabular}{|c|c|c|c|c|c|}
\hline & Unsorted (\%) & Paper $(\%)$ & GFT (\%) & Glass (\%) & Textile $(\%)$ \\
\hline \multicolumn{6}{|l|}{ (a) } \\
\hline Household size & -0.0320 & 0.0049 & $0.0782 * *$ & -0.0108 & $-0.0134 * * *$ \\
\hline Population density & -0.0150 & 0.0029 & 0.0161 & -0.0043 & 0.0012 \\
\hline Municipalities 20-50 & -0.0012 & 0.0017 & 0.0016 & 0.0010 & -0.0023 \\
\hline Municipalities 50-100 & 0.0148 & 0.0016 & -0.0135 & -0.0009 & -0.0021 \\
\hline Municipalities > 100 & -0.0320 & 0.0084 & 0.0039 & 0.0047 & 0.0013 \\
\hline Ethnicity & $0.0139 * *$ & -0.0002 & $-0.0116^{*}$ & 0.0004 & -0.0009 \\
\hline Income & -0.0191 & 0.0083 & 0.0026 & $0.0056 *$ & $0.0046 *$ \\
\hline UBP: volume & -0.0059 & $0.0092 *$ & $0.0176^{* * *}$ & -0.0006 & $-0.0018^{* * *}$ \\
\hline UBP: frequency & -0.0054 & $0.0474 * * *$ & $-0.0448 * * *$ & $0.0138 * * *$ & 0.0000 \\
\hline UPB: bag & $-0.1269 * * *$ & $0.0306^{* * *}$ & $0.0907 * * *$ & $0.0117 * * *$ & 0.0009 \\
\hline UBP: weight & $-0.0307 * *$ & $0.0971 * * *$ & $-0.0954 * * *$ & $0.0274 * * *$ & 0.0017 \\
\hline UBPcurbside & $-0.0052 * * *$ & 0.0005 & $-0.0023^{*}$ & $0.0007 *$ & $0.0006^{* * *} *$ \\
\hline Frequency: paper & $-0.0002 *$ & $0.0001 *$ & $0.0001 *$ & 0.0000 & 0.0000 \\
\hline Frequency: GFT & $0.0004 * * *$ & 0.0000 & $-0.0004 * * *$ & 0.0000 & $0.0000^{*}$ \\
\hline Frequency: glass & -0.0002 & 0.0001 & -0.0001 & $0.0001 *$ & 0.0000 \\
\hline Frequency: textile & $-0.0001 *$ & 0.0000 & 0.0001 & 0.0000 & 0.0000 \\
\hline $\mathrm{R}^{2}$ & 0.51 & 0.56 & 0.44 & 0.42 & 0.08 \\
\hline Observations & 5321 & 5321 & 5321 & 5321 & 5321 \\
\hline \multicolumn{6}{|l|}{ (b) } \\
\hline Household size & -0.0312 & 0.0034 & $0.0719^{*}$ & -0.0090 & $-0.0132 * * *$ \\
\hline Population density & -0.0153 & 0.0026 & 0.0174 & -0.0045 & 0.0012 \\
\hline Municipalities 20-50 & -0.0020 & 0.0004 & 0.0030 & 0.0016 & -0.0024 \\
\hline Municipalities 50-100 & 0.0141 & 0.0005 & -0.0125 & -0.0002 & -0.0021 \\
\hline Municipalities $>100$ & -0.0327 & 0.0073 & 0.0047 & 0.0054 & 0.0013 \\
\hline Ethnicity & $0.0138 * *$ & -0.0005 & $-0.0112 *$ & 0.0002 & -0.0009 \\
\hline Income & -0.0186 & 0.0103 & 0.0018 & $0.0058^{*}$ & $0.0046^{*}$ \\
\hline UBP: volume & -0.0049 & 0.0010 & 0.0077 & 0.0006 & $-0.0015^{*}$ \\
\hline UBP: frequency & -0.0083 & $0.0421 * * *$ & $-0.0303 * * *$ & $0.0086^{* * *}$ & -0.0004 \\
\hline UPB: bag & $-0.1162 * * *$ & $0.0506^{* * *}$ & $0.0658 * * *$ & $0.0098 * *$ & 0.0015 \\
\hline UBP: weight & $-0.0426^{* *}$ & $0.0926^{* * *}$ & $-0.0786^{* * * *}$ & $0.0449 * * *$ & 0.0013 \\
\hline UBPvolumecurbside & $-0.0055^{* *}$ & $0.0030 * *$ & 0.0007 & 0.0004 & $0.0005 * * *$ \\
\hline UBPfrequencycurbside & $-0.0044 * *$ & 0.0018 & $-0.0061 * * *$ & $0.0021 * * *$ & $0.0007 * * *$ \\
\hline UBPbagcurbside & $-0.0088^{* *}$ & $-0.0065 * * *$ & $0.0060 * *$ & $0.0014 * *$ & 0.0004 \\
\hline UBPweightcurbside & -0.0023 & 0.0016 & $-0.0064 * * *$ & $-0.0036^{* *}$ & 0.0007 \\
\hline Frequency: paper & $-0.0002 *$ & $0.0001 *$ & 0.0001 & 0.0000 & 0.0000 \\
\hline Frequency: GFT & $0.0004 * * *$ & 0.0000 & $-0.0004 * * *$ & 0.0000 & $0.0000 *$ \\
\hline Frequency: glass & -0.0002 & 0.0000 & 0.0000 & $0.0001 * *$ & 0.0000 \\
\hline Frequency: textile & $-0.0001 *$ & 0.0000 & 0.0001 & 0.0000 & 0.0000 \\
\hline $\mathrm{R}^{2}$ & 0.51 & 0.56 & 0.44 & 0.42 & 0.08 \\
\hline Observations & 5321 & 5321 & 5321 & 5321 & 5321 \\
\hline
\end{tabular}

$* * * ; * ; *$ Significance at the $99 \%$; $95 \%$; $90 \%$ level. Models estimated with municipal and year fixed effects 
the recycling materials the effects are in many cases insignificant and for all cases smaller than $0.1 \%$ point. Our conclusion is that the interaction between UBP systems and curbside recycling efforts are not driving our results. ${ }^{33}$

\section{Conclusions}

In the Netherlands, there is a long history of policies to stimulate household recycling of waste. On average, Dutch municipalities recycle approximately $50 \%$ and only a small number of municipalities recycle more than $65 \%$, the goal that has been announced by the EU. For achieving this goal-more than in most other European countries- the Netherlands relies almost entirely on households' separation of waste. By using panel data for 1998-2012, we explain recycling rates for household waste. We explore which policies are effective in increasing the recycling rates for different materials-paper, glass, textiles, compostable waste and, from 2007 onwards, plastic packaging. Our main conclusion is that it will be hard to achieve the $65 \%$ EU goal as not many policies have a significant and large effect on recycling rates.

In line with earlier contributions [for example, Dijkgraaf and Gradus (2004, 2015)], we show that unit-based pricing systems as the bag, weight- and frequency -based systems are effective, as the reductions in unsorted waste are sizeable and the amounts of recyclables collected increase substantially. However, even for these policies the effects are no larger than $10 \%$ points, while most effects are only a few percentage points on average. It should be noted that in case of low recycling rates, introducing UBP will have larger effect at the margin. Furthermore, these systems can have some adverse effects such as administrative costs and measures needing to be taken to avoid illegal dumping. The bag-based system can be more effective in reducing unsorted waste but it has additional adverse effects on home composting and in the Netherlands there are problems with carrying these bags, smells and bags bursting especially in coastal regions with many gulls or other birds. These last problems are not necessarily applicable to other countries. As the frequency-based system has less administrative costs, the number of large cities with a frequency-based pricing system has increased in recent years [see also Dijkgraaf and Gradus (2015)].

Interestingly, we find that avoiding a duo-bin for unsorted and compostable waste decreases the unsorted waste rate by more than $3 \%$ points. In addition, introducing a separate bag (or bin) for plastics decreases this rate with more than $1 \%$ points as well. Also, reducing the frequency of collecting unsorted waste is effective in raising the recycling rate. If, for example, unsorted waste is collected fortnightly instead of weekly, the recycling rate goes up by $1.3 \%$ points. This effect is smaller for recyclables. For example, in municipalities where volunteers collect paper door-to-door, the paper recycling rate is $0.5 \%$ points higher. So, these policies are nowhere near enough to fill the gap between the current recycling level and the EU goal. This brings us to the conclusion that the goal of $65 \%$ is out of reach for most municipalities based on the available policies. Nevertheless, some policies such as avoiding a duo-bin are advisable from a recycling point of view and can therefore be advocated.

Importantly, other explanations for the recycling rate are social norms and socio-economic circumstances [see also Abbott et al. (2013, 2014)], which can only be partly influenced by

33 There can be several possible explanations for the difference of our results with that of Palatnik et al. (2014). First, we have municipal panel data (1998-2012) and they have a cross-section based on household data. Second, they include different control data. For instance, only with a panel fixed effects can be included that correct for not observed heterogeneity. We leave it as a topic for future research to compare the results for the different countries when more data become available and guaranteeing that methodologies are more comparable. 
politics. We find that a higher share of non-western ethnic groups implies more unsorted waste. Furthermore, household size plays a role in explaining the recycling rates for plastics, compostable material and textiles. Based on these estimations, it can be argued that larger cities with many non-western people, a small average household size and fewer possibilities for composting are less likely to achieve higher recycling rates. Interestingly, in 2007-2012, larger cities have a significantly higher recycling rate for textiles, which could reflect the increase in the number of thrift shops after the crisis in these cities. In addition, we also show that in case of low recycling rates, the effects on (total) recycling of especially the weight -and frequency pricing systems increase, but this will not change the conclusion of the difficult to reach $65 \%$ goal as the gap to close will be larger as well for these low recycling municipalities. Finally, contrary to Palatnik et al. (2014), we do not find robust interaction effects between unit-based pricing and curbside collection efforts.

There are many avenues to explore in future research. First, further explanation of Dutch recycling rates could be of interest. The literature has shown that the educational attainment and age profile of citizens in a municipality are especially important in explaining these rates [see Abbott et al. (2013)]. Second, it is important to have more data available, especially for container type, plastics and the frequency of collecting unsorted waste. Information on the size of containers is particularly important for a further investigation. Third, a municipality's decisions can be influenced by neighboring municipalities-for example, if collection is combined or if external effects are present (such as illegal dumping in other municipalities); this could be tested using spatial models [see Brueckner (2003)]. Fourth, estimating the social cost functions of different recycling options could also be of interest. Recently, Kinnaman et al. (2014) showed that average social costs are minimized with recycling rates well below mandated levels in Japan. Based upon the results of that paper, it appears that the $20 \%$ recycling rate in Japan is higher than the socially optimal rate (10\%). There is some evidence that this is the case for Europe as well. Hereby, a cost-benefit analysis based on industrial recycling instead of household recycling is worthwhile.

Open Access This article is distributed under the terms of the Creative Commons Attribution 4.0 International License (http://creativecommons.org/licenses/by/4.0/), which permits unrestricted use, distribution, and reproduction in any medium, provided you give appropriate credit to the original author(s) and the source, provide a link to the Creative Commons license, and indicate if changes were made.

\section{Appendix 1: Definition of Variables}

$\begin{array}{cc}\text { Unsorted waste as \% total } & \text { Collected unsorted waste per inhabitant as a percentage of total collected } \\ \text { collected waste } & \text { waste per inhabitant } \\ \text { Compostable waste as } \% & \text { Separately collected compostable waste per inhabitant as a percentage of } \\ \text { total collected waste } & \text { total collected waste per inhabitant } \\ \text { Paper waste as \% total } & \text { Separately collected paper waste per inhabitant as a percentage of total } \\ \text { collected waste } & \text { collected waste per inhabitant } \\ \text { Glass waste as \% total } & \text { Separately collected glass waste per inhabitant as a percentage of total } \\ \text { collected waste } & \text { collected waste per inhabitant } \\ \text { Textile waste as } \% \text { total } & \text { Separately collected textile waste per inhabitant as a percentage of total } \\ \text { collected waste } & \text { collected waste per inhabitant } \\ \text { Plastic waste as } \% \text { total } & \text { Separately collected plastic waste per inhabitant as a percentage of total } \\ \text { collected waste } & \text { collected waste per inhabitant }\end{array}$




Household size
Population density
Municipalities 20-50
Municipalities 50-100
Municipalities >100
Ethnicity
Income
UBP: volume
UBP: frequency
UBP: bag
UBP: weight
UBP: volume, low
recycling
UBP: frequency, low
recycling
UPB: bag, low recycling
UBP: weight, low
recycling
UBPcurbside

UBPvolumecurbside

UBPfrequencycurbside

UBPbagcurbside

UBPweightcurbside

Bring: paper (dum) Bring: glass (dum) Bring: textile (dum) Frequency: unsorted Frequency: compost Frequency: paper Frequency: glass Frequency: textile Frequency: plastic Unsorted: duo-bin Unsorted: mini-bin Unsorted: bag Unsorted: crate Compost: duo-bin

Compost: mini-bin

Compost: bag
Number of inhabitants per household

Municipal area in square kilometers per household

Dummy is 1 if municipalities have number of inhabitants between 20,000 and 50,000

Dummy is 1 if municipalities have number of inhabitants between 50,000 and 100,000

Dummy is 1 if municipalities have number of inhabitants more than 100,000

Share of non-western people (born in or parents from non-Western country) in total number of inhabitants

Income per inhabitant in thousand euro

Dummy is 1 if volume-based pricing system is present and 0 otherwise

Dummy is 1 if frequency-based pricing system is present and 0 otherwise

Dummy is 1 if bag-based pricing system is present and 0 otherwise

Dummy is 1 if weight-based pricing system is present and 0 otherwise

Dummy is 1 if volume-based pricing system is present and municipality has below average recycling in 1998

Dummy is 1 if frequency-based pricing system is present and municipality has below average recycling in 1998

Dummy is 1 if bag-based pricing system is present and municipality has below average recycling in 1998

Dummy is 1 if weight-based pricing system is present and municipality has below average recycling in 1998

Variable with value 0 if UBP and no curbside collection, 1 if UBP and curbside collection for one material, 2 if UBP and curbside collection for two materials, etc.

Variable with value 0 if UBP volume and no curbside collection, 1 if UBP volume and curbside collection for one material, 2 if UBP volume and curbside collection for two materials, etc.

Variable with value 0 if UBP frequency and no curbside collection, 1 if UBP frequency and curbside collection for one material, 2 if UBP frequency and curbside collection for two materials, etc.

Variable with value 0 if UBP bag and no curbside collection, 1 if UBP bag and curbside collection for one material, 2 if UBP bag and curbside collection for two materials, etc.

Variable with value 0 if UBP weight and no curbside collection, 1 if UBP weight and curbside collection for one material, 2 if UBP weight and curbside collection for two materials, etc.

Dummy is 1 if municipality has a bring system for paper

Dummy is 1 if municipality has a bring system for glass

Dummy is 1 if municipality has a bring system for textiles

Number of times a year unsorted waste is collected at the curbside

Number of times a year compostable waste is collected at the curbside

Number of times a year paper waste is collected at the curbside

Number of times a year glass waste is collected at the curbside

Number of times a year textile waste is collected at the curbside

Number of times a year plastic waste is collected at the curbside

Dummy is 1 if unsorted waste is collected at the curbside from a duo-bin

Dummy is 1 if unsorted waste is collected at the curbside from a mini-bin

Dummy is 1 if unsorted waste is collected at the curbside from a bag

Dummy is 1 if unsorted waste is collected at the curbside from a crate

Dummy is 1 if compostable waste is collected at the curbside from a duo-bin

Dummy is 1 if compostable waste is collected at the curbside from a mini-bin

Dummy is 1 if compostable waste is collected at the curbside from a bag 
Compost: crate

Paper: duo-bin

Paper: mini-bin

Paper: bag

Paper: crate

Glass: duo-bin

Glass: mini-bin

Glass: bag

Glass: crate

Textile: duo-bin

Textile: mini-bin

Textile: bag

Textile: crate

Plastic: duo-bin

Plastic: mini-bin

Plastic: bag

Plastic: crate

Volunteer
Dummy is 1 if compostable waste is collected at the curbside from a crate Dummy is 1 if paper waste is collected at the curbside from a duo-bin Dummy is 1 if paper waste is collected at the curbside from a mini-bin Dummy is 1 if paper waste is collected at the curbside from a bag Dummy is 1 if paper waste is collected at the curbside from a crate Dummy is 1 if glass waste is collected at the curbside from a duo-bin Dummy is 1 if glass waste is collected at the curbside from a mini-bin Dummy is 1 if glass waste is collected at the curbside from a bag Dummy is 1 if glass waste is collected at the curbside from a crate Dummy is 1 if textile waste is collected at the curbside from a duo-bin Dummy is 1 if textile waste is collected at the curbside from a mini-bin Dummy is 1 if textile waste is collected at the curbside from a bag Dummy is 1 if textile waste is collected at the curbside from a crate Dummy is 1 if plastic waste is collected at the curbside from a duo-bin Dummy is 1 if plastic waste is collected at the curbside from a mini-bin Dummy is 1 if plastic waste is collected at the curbside from a bag Dummy is 1 if plastic waste is collected at the curbside from a crate Dummy is 1 if volunteer organization(s) collect paper in municipality

\section{Appendix 2: The Endogeneity Issue}

We include three different proxy variables and test for endogeneity of a UBP policy and frequency policies by estimating three models:

- First, we try to capture the possible endogeneity of the UBP and frequency variables by using their lagged values in our estimation [see also Usui and Takeuchi (2013)]. Thereby, we control for announcement effects.

- Second, we include a dummy variable Bring locations of the kth-materials with value 1 if there are collection points for the kth material. It can capture the impact of any supplemental policies introduced together with curbside collection. Even if there is curbside collection, in many Dutch municipalities citizens can also deliver recyclables to collection points at central locations such as shopping centres and town halls.

- Third, we include an environmental activism dummy, which tests whether early movers are more environmentally orientated than municipalities that introduce unit-based pricing in later years. ${ }^{34}$

In Tables 6, 7, 8 these models are tested for the full panel and five materials (unsorted, paper, compostable, glass and textile). Results are quite similar among these models. We do find some but not very strong evidence of an announcement effect from a UBP and frequency policies on recycling rates (see Table 6). While we find some evidence of an announcement effect for the frequency-based system, there is no such effect in the weight-based system, volume-based and bag-based systems. In addition, we find some evidence of an announcement effect for the GFT- and textile-frequency of curbside collection but not for paper and glass. The estimation results including the Bring-dummy are almost similar to the base model (see Table 7). The announcement effect can be driven by an environmental activism effect [see also Linderhof et al. (2001)]. Dutch municipalities that introduced curbside collection or an UBP policy might be more environmentally orientated than municipalities that introduced such policies in later years. This was tested in Table 8, where we introduce an environmental activism dummy. This tests whether municipalities that have already introduced UBP or

34 The environmental activism dummy has the value 1 in all years for each municipality that introduces a specific unit-based pricing system in one of the specified years [see also Dijkgraaf and Gradus (2009)]. 


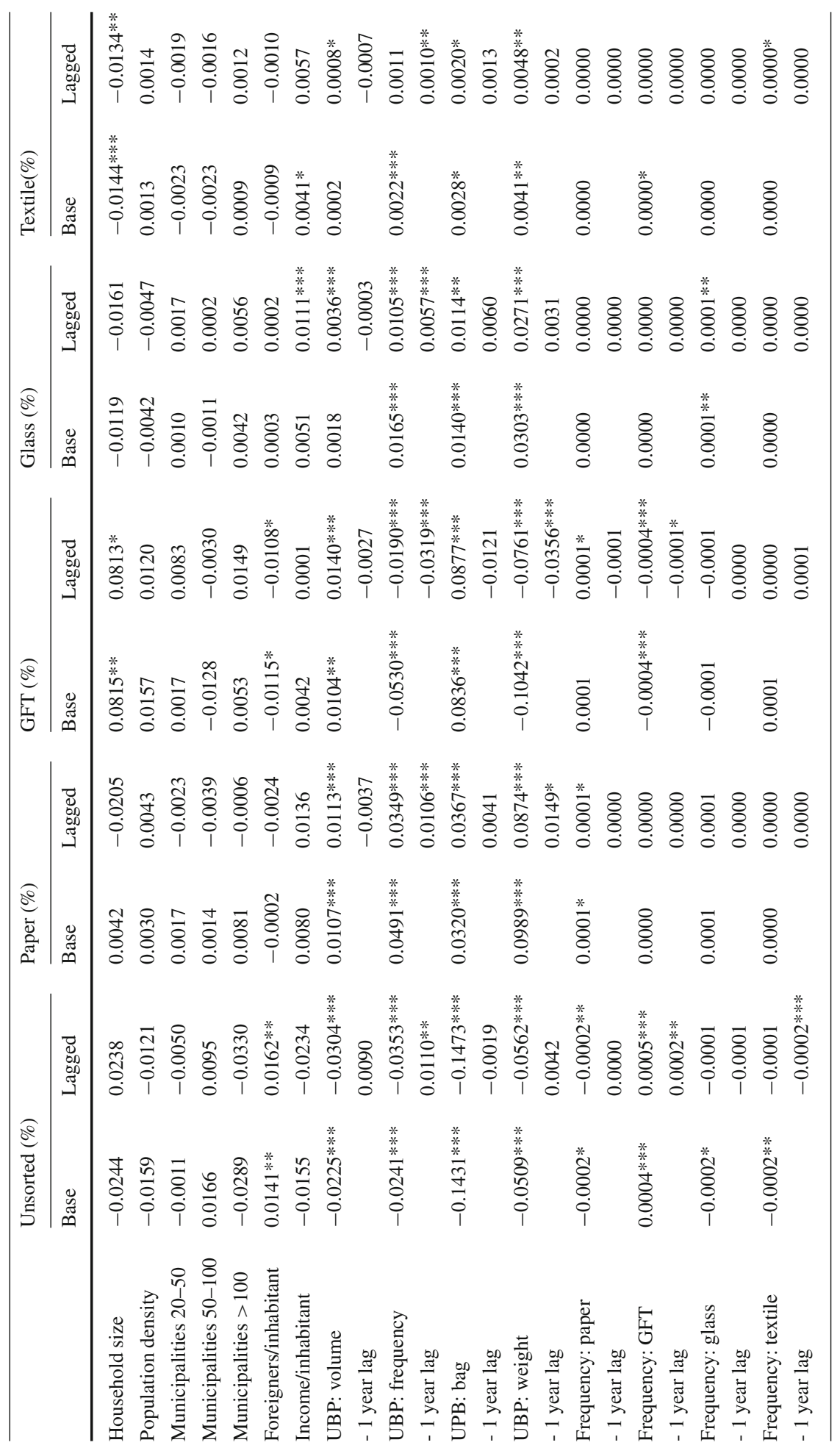




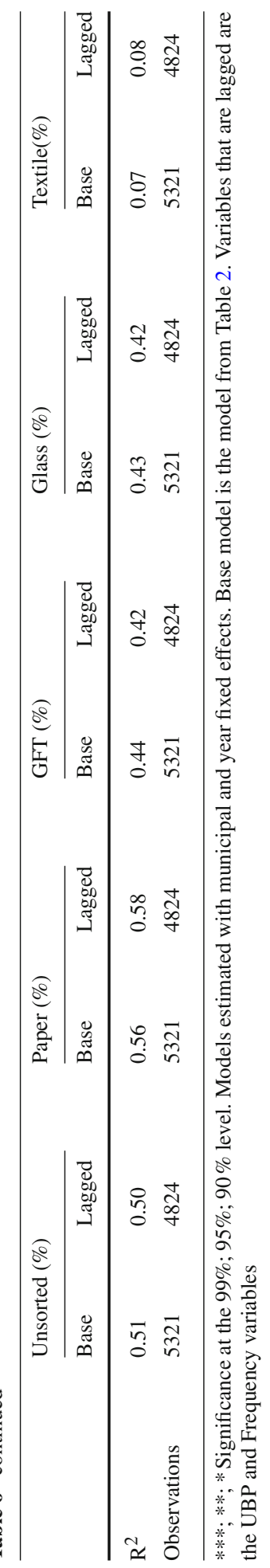

\section{G) Springer}


Table 7 Estimated models with bring variable

\begin{tabular}{|c|c|c|c|c|c|}
\hline & Unsorted (\%) & Paper (\%) & Compost (\%) & Glass (\%) & Textile (\%) \\
\hline Household size & -0.0232 & 0.0039 & $0.0804 * *$ & -0.0117 & $-0.0144 * * *$ \\
\hline Population density & -0.0159 & 0.0029 & 0.0159 & -0.0043 & 0.0012 \\
\hline Municipalities 20-50 & -0.0010 & 0.0018 & 0.0013 & 0.0012 & -0.0023 \\
\hline Municipalities 50-100 & 0.0164 & 0.0014 & -0.0127 & -0.0011 & -0.0022 \\
\hline Municipalities > 100 & -0.0302 & 0.0084 & 0.0063 & 0.0042 & 0.0012 \\
\hline Foreigners/inhabitant & $0.0143 * *$ & -0.0002 & $-0.0117^{*}$ & 0.0004 & -0.0009 \\
\hline Income/inhabitant & -0.0146 & 0.0079 & 0.0030 & 0.0054 & $0.0041^{*}$ \\
\hline UBP: volume & $-0.0222 * * *$ & $0.0106 * * *$ & $0.0101 * *$ & 0.0018 & 0.0002 \\
\hline UBP: frequency & $-0.0243 * * *$ & $0.0490 * * *$ & $-0.0527 * * *$ & $0.0164 * * *$ & $0.0023 * * *$ \\
\hline UBP: bag & $-0.1432 * * *$ & $0.0321 * * *$ & $0.0835 * * *$ & $0.0140 * * *$ & 0.0028 \\
\hline UBP: weight & $-0.0515^{* * *}$ & $0.0989 * * *$ & $-0.1035^{* * *}$ & $0.0302 * * *$ & $0.0042 * *$ \\
\hline Frequency: paper & $-0.0002 *$ & $0.0001 *$ & 0.0001 & 0.0000 & 0.0000 \\
\hline Frequency: compost & $0.0004^{* * *}$ & 0.0000 & $-0.0004 * * *$ & 0.0000 & $0.0000 * *$ \\
\hline Frequency: glass & $-0.0002 *$ & 0.0001 & -0.0001 & $0.0001 * *$ & 0.0000 \\
\hline Frequency: textile & $-0.0001 *$ & 0.0000 & 0.0001 & 0.0000 & 0.0000 \\
\hline Bring: paper (dum) & -0.0029 & 0.0005 & $0.0033 *$ & -0.0007 & -0.0001 \\
\hline Bring: glass (dum) & -0.0010 & -0.0006 & 0.0022 & -0.0003 & 0.0003 \\
\hline Bring: textile (dum) & 0.0005 & 0.0010 & $-0.0028 *$ & 0.0009 & 0.0003 \\
\hline $\mathrm{R}^{2}$ & 0.51 & 0.55 & 0.44 & 0.42 & 0.08 \\
\hline Observations & 5321 & 5321 & 5321 & 5321 & 5321 \\
\hline
\end{tabular}

***; **; * Significance at the $99 \% ; 95 \% ; 90 \%$ level. Models estimated with municipal and year fixed effects

curbside collection had higher recycling rates before introduction, because they were more environmentally friendly. Table 8 shows that there is some environmental activism effect for UBP and frequency systems, although it becomes smaller if time is progressing. The only problem with the activism model in Table 8 is that we have to exclude fixed effects as it is impossible to combine fixed effects and the environmental activism dummy. Therefore, we estimate the base without fixed effects as well in and results are given as well in Table 8. If we compare for the UBP system and the frequency variables, the base model with the model with environmental activism the estimates are again quite similar. As results are quite similar among the models, there is no indication for endogeneity. Therefore, we confine the discussion in the main text to the base model in Eq. (1). 


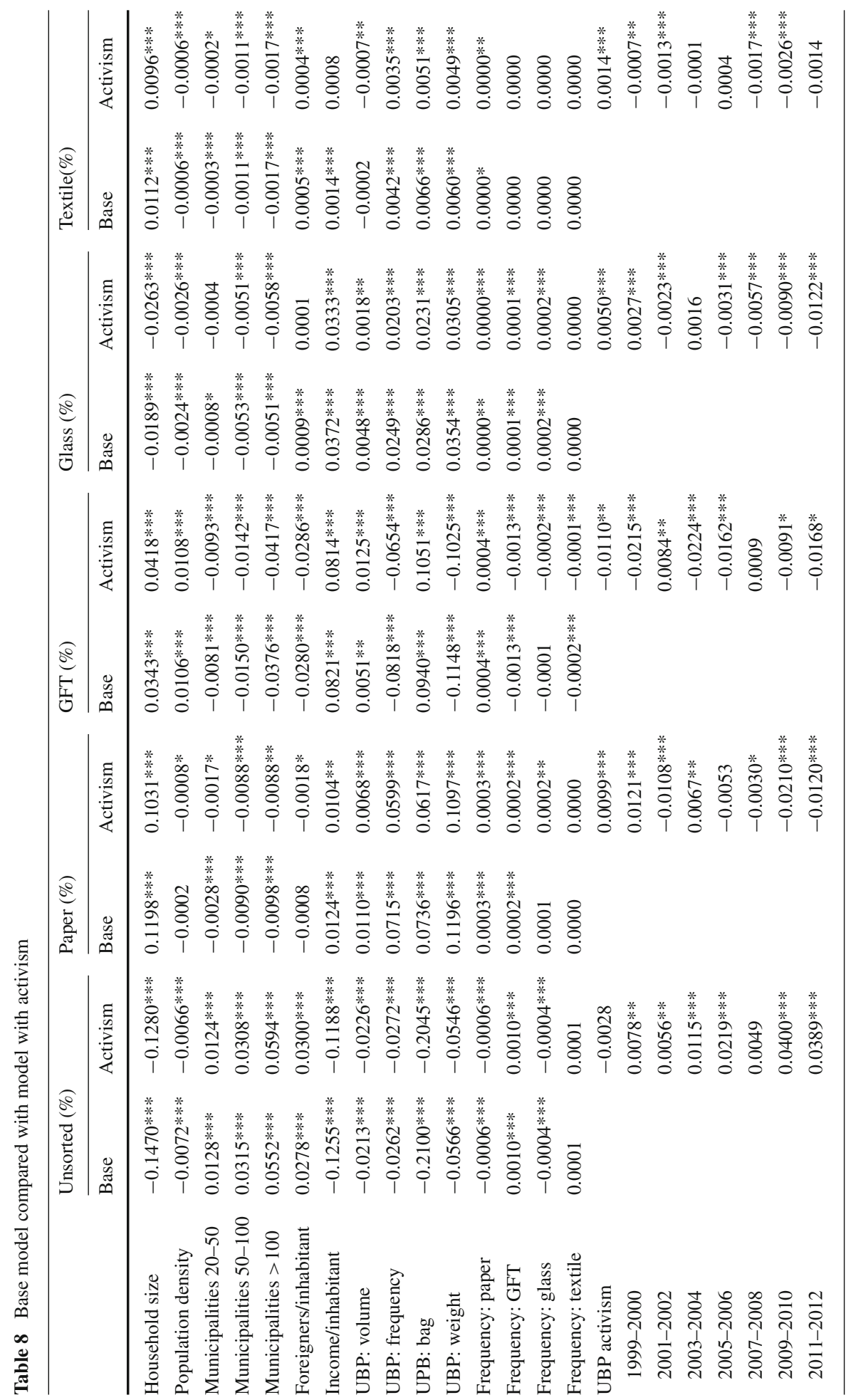




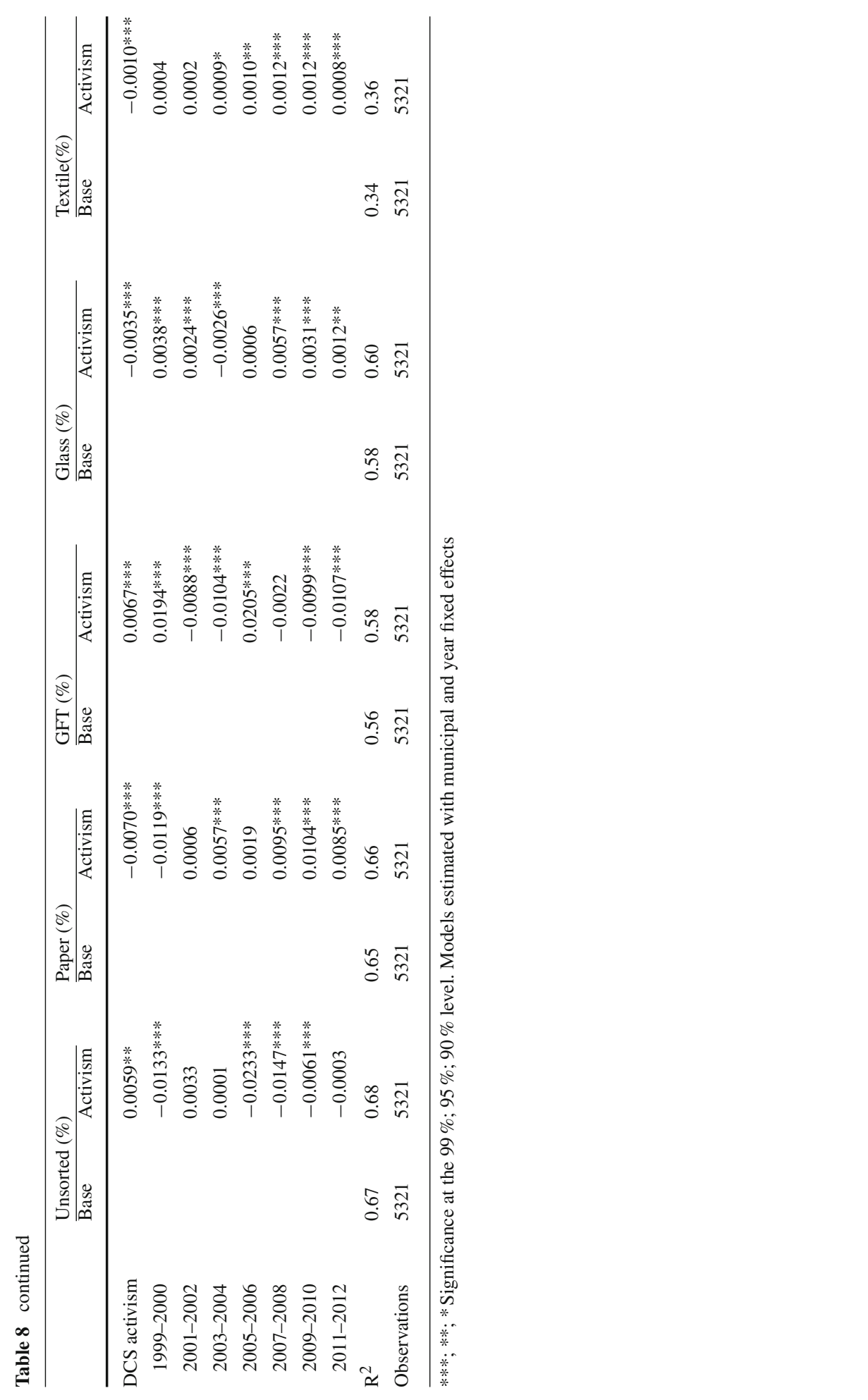




\section{References}

Abbott A, Nandeibam S, O'Shea L (2011) Explaining the variation in household recycling rates across the UK. Ecol Econ 70(11):2214-23

Abbott A, Nandeibam S, O'Shea L (2013) Recycling: social norms and warm-glow revisited. Ecol Econ 90:10-18

Abbott A, Nandeibam S, O’Shea L (2014) Is there a social norm to recycle? In: Kinnaman T, Takeuchi K (eds) Handbook on waste management. Edward Elgar Publishers, Cheltenham, pp 53-74

Allers M, Hoeben C (2010) Effects of unit-based garbage pricing: a differences-in-differences approach. Environ Resour Econ 45(3):405-428

Beatty T, Berck P, Shimshack JP (2007) Curbside recycling in the presence of alternatives. Econ Inq 45(4):739_ 55

Bel G, Gradus RHJM (2016) Effects of unit-based pricing on the waste collection demand: a meta-regression analysis. Resour Energy Econ 44:169-182

Brueckner J (2003) Strategic interaction among governments: an overview of empirical studies. Int Reg Urban Econ 26(2):175-188

Callan SJ, Thomas JM (1997) The impact of state and local policies on the recycling effort. East Econ J 23(4):411-423

Callan SJ, Thomas JM (2001) Economics of scale and scope: a cost analysis of municipal solid waste services. Land Econ 77(4):548-560

Dijkgraaf E, Gradus RHJM (2004) Cost savings in unit-based pricing of household waste: the case of the Netherlands. Resour Energy Econ 26(4):353-371

Dijkgraaf E, Gradus RHJM (2009) Dynamics of unit-based pricing systems and environmental activism. Resour Energy Econ 31(1):13-23

Dijkgraaf E, Gradus RHJM (2014) Waste management in the Netherlands. In: Kinnaman T, Takeuchi K (eds) Handbook on waste management. Edward Elgar Publishers, Cheltenham, pp 287-315

Dijkgraaf E, Gradus RHJM (2015) Efficiency effects of unit-based pricing systems and institutional choices of waste collection. Environ Resour Econ 61(4):641-650

Eurostat (2014) $42 \%$ of EU28 treated municipal waste was recycled or composted in 2012, Press Release, 25 March 2014

Ferrera I, Missios P (2005) Recycling and waste diversion effectiveness: evidence from Canada. Environ Resour Econ 30(2):221-238

Fullerton D, Kinnaman TC (1996) Household responses to pricing garbage by the bag. Am Econ Rev 86(4):971-84

Groenewold A, Spronk L (2012) Afvalrizoom: droom of toekomst?. Emmen, Van Afval naar Grondstof, Area Reiniging NV (in Dutch)

Huang JC, Halstead JM, Saunders SB (2011) Managing municipal solid waste with unit-based pricing: policy effects and responsiveness to pricing. Land Econ 87:645-660

Kinnaman TC, Fullerton D (2000) Garbage and recycling with endogenous local policy. J Urban Econ 48(3):419-442

Kinnaman TC, Shinkuma T, Yamamoto M (2014) The socially optimal recycling rate: evidence from Japan. J Environ Econ Manag 68(1):54-70

Kipperberg G (2007) A comparison of household recycling behaviors in Norway and the United States. Environ Resour Econ 36(2):215-235

Lakhan C (2015) Evaluating the effects of unit based waste disposal schemes on the collection of household recyclables in Ontario. Can Resour Conserv Recycl 95:38-45

Linderhof V, Kooreman P, Allers M, Wiersma D (2001) Weight-based pricing in the collection of household waste: the Oostzaan case. Resour Energy Econ 23(4):359-71

Miranda ML, Aldy JE (1998) Unit pricing of residential municipal solid waste: lessons from nine case study communities. J Environ Manag 52:79-93

Nichols A, Schaffer M (2007) Clustered errors in Stata, http://www.stata.com/meeting/13uk/nichols_crse.pdf

Palatnik R, Body S, Ayalon O, Shechter M (2014) Greening household behaviour and waste. OECD Environment Working Paper 76

Reus P, Jonkergouw N (2013) Verkenning inzamelsystemen en inzamelpilots. SRE Milieudienst, Eindhoven [in Dutch]

Usui T, Takeuchi K (2013) Evaluating unit-based pricing of residential solid waste: a panel data analysis. Environ Resour Econ 58:245-271

Usui $\mathrm{T}$ (2008) Estimating the effect of unit-based pricing in the presence of sample selection bias under Japanese recycling law. Ecol Econ 66(2-3):282-8 